\title{
Gaseous and adsorbed PAH in an iron foundry
}

\author{
U KNECHT, H-J ELLIEHAUSEN, H-J WOITOWITZ \\ From the Institute and Policlinic for Occupational and Social Medicine, University of Giessen, 6300 Giessen, \\ West Germany
}

ABSTRACT The increased risk of lung cancer among foundry workers is assumed to be associated with the inhalation of gaseous and particle bound polycyclic aromatic hydrocarbons (PAH). These compounds are produced during pyrolysis of carbon containing loading material in the moulding sand. The concentrations of $20 \mathrm{PAH}$, some of which are carcinogenic, have been determined in the dusty casting area of an iron foundry by means of gas chromatography and mass spectrometry. The total dust was fractionated by means of a precision cascade impactor. It was possible to differentiate the PAH load in $\mu \mathrm{g} / \mathrm{mg}$ dust in seven particle size fractions ranging from $0.36-\geqslant 24.95 \mu \mathrm{m}$. Initially, there was an increase of the adsorbed PAH mass concentration with increasing particle diameter up to a maximum of $1.1 \mu \mathrm{g} / \mathrm{mg}$ in the dust of the $1.57 \mu \mathrm{m}$ fraction. Thereafter there was a continuous decrease of PAH mass concentration with increasing particle size. When the differing weights of the seven fractions are taken into account, however, the total PAH load of the individual fractions increases steadily with increasing particle size. The inhalable fine dust, $31.4 \%$ of the total dust, contains $49.9 \%$ of the total adsorbed PAH. The gas phase contained on average three times more carcinogenic PAH with four and five rings than was adsorbed on the dust. Thus the percentage of the gaseous substances amounts to $77 \%$ of the total PAH load at the place of work in an iron foundry.

Complex mixtures of airborne pollutants have been detected at places of work in iron foundries. ${ }^{12}$ The risks of silicosis and obstructive lung disease for iron foundry workers are well known. Furthermore, an increase in lung cancer has been observed epidemiologically. ${ }^{3-6}$ On the basis of existing data, it is not possible to substantiate a causal relation between exposure to pure quartz dust and an excess risk of lung cancer. ${ }^{7-9}$ Nevertheless, associations between exposure to quartz dust and cancer of the respiratory organs were observed at those workplaces in which exposure to polycyclic aromatic hydrocarbons (PAH) and other gaseous and particulate emissions can occur. Animal experiments have shown that the extremely complex class of PAH contains many known or suspected carcinogens. The possibility of synergistic interaction of some of these compounds with certain carcinogens has also to be taken into consideration.

PAH are produced by the pyrolysis of organic materials. One place where this may occur is in iron foundries since some of the iron founding processes lead to pyrolytic reactions. Organic materials are added to the moulding sand in the series production

Accepted 24 March 1986 of hollow grey iron castings. In the hot box technique modified furan resins serve as mould and core binders. Admixed hard coal powder is used to avoid undesirable iron-sand reactions by forming lustrous carbon at the temperature of molten iron-about $1400^{\circ} \mathrm{C}$. The PAH formed and released by pyrolysis in a limited oxygen supply can appear free in the gaseous form and adsorbed on to dust particles.

The assessment of the medical risk is based on the analysis of airborne PAH concentrations. Furthermore, this assessment has to differentiate the amount of PAH present in both the gaseous and the dust adsorbed forms.

The deposition of inhaled dusts depends largely on particle size. We therefore investigated the particle size distribution of the dust and the pattern of PAH adsorption on to it. Since the highest dust concentrations have been found where the castings are removed from the moulds, ${ }^{2}$ PAH profile at this site has been analysed.

\section{Material and methods}

\section{AIR AND DUST SAMPLING}

Total dust samples were taken at stationary sites on 12 different days in an iron foundry at the point where 
the castings are shaken out of their moulds. ${ }^{10}$ The aim was to obtain a representative dust sample sufficiently large enough for fractionation. The air samples were absorbed into toluene by the use of impingers and particulate matter was collected on glass fibre filters.

\section{PARTICLE SIZE FRACTIONATION}

A precision cascade impactor was used in the laboratory to fractionate the collected dust samples. A total of seven fractions was obtained having aerodynamic diameters of between about 0.3 and $30 \mu \mathrm{m}$. The impactor was calibrated using particles of known size. The discrimination of the impactor was such that the isolated fractions may be described in terms of mean particle sizes.

\section{CLEAN UP AND ANALYTICAL PROCEDURES}

The toluene solutions were dried over sodium sulphate, concentrated, and analysed by glass capillary gas chromatography (GCGC) combined with mass spectrometry. The preparation of the seven fractioned dust samples for subsequent qualitative/quantitative analysis was performed according to Grimmer and Böhnke $^{11}$ and Griest and Caton. ${ }^{12}$ PAH profile analyses were carried out by gas chromatography/ mass spectrometry using reference standards.

\section{Results}

The density necessary for determining the particle size of the airborne dust samples is $1.69 \mathrm{~g} / \mathrm{m}^{3}$. A total of seven fractions were separated from the whole dustthat is, total respirable dust-obtained at the site where the castings are shaken out of their moulds. Their particle size and weight distributions are reported in table 1 .

The total dust concentration (mean $\pm \mathrm{SD}$ ) was $9.58 \pm 4.72 \mathrm{mg} / \mathrm{m}^{3}$. The amount of fine dust - that is, dust which may reach the alveoli and be exhaled again - was about $31 \%$ of the total dust. Previous measurements at the same site yielded fine dust mass concentrations of $3.01 \pm 1.50 \mathrm{mg} / \mathrm{m}^{3}{ }^{2}$.

Gas chromatographic/mass spectrometric analysis resulted in the identification of $20 \mathrm{PAH}$, in both the particulate matter and in the gaseous phase. These substances possess differing carcinogenic and mutagenic activities (table 2).

Neither the b-, j-, and k-isomers of the benzofluoranthene nor chrysene and triphenylene can be separated by gas chromatography. The fact that these isomers have equal molecular weights and similar fragmentation patterns mean that they cannot be differentiated by mass spectroscopy. The two groups are therefore reported as the sums of their respective isomeric components.

Figure 1 shows the total amount of PAH of the seven particle size fractions in $\mu \mathrm{g} \mathrm{PAH} / \mathrm{mg}$ dust fraction. At first, the mass of PAH adsorbed increases with increasing particle size. The fraction with a mean particle size of $1.57 \mu \mathrm{m}$ has the highest content of around $1 \cdot 1 \mu \mathrm{g} \mathrm{PAH} / \mathrm{mg}$ dust. With further increase in particle size, the adsorbed PAH load continuously decreases. The $\geqslant 24.95 \mu \mathrm{m}$ fraction has the lowest PAH concentration with $0.28 \mu \mathrm{g}$ PAH/mg dust.

The percentage distribution of five selected $\mathrm{PAH},{ }^{22}$ distributed among the seven particle size fractions shows little deviation from that of all 20 PAH taken together (fig 2). Thus the concentration of a particular compound is similar throughout the whole particle size spectrum.

The PAH distribution is different, however, when the weight of the seven particle size fractions is taken into account (fig 3). As may be seen, except for the $6.26 \mu \mathrm{m}$ fraction, the total mass of the $20 \mathrm{PAH}$ in the individual fractions increases with increasing particle size.

The weights of the individual fractions are decisive for this. Thus the $0.36 \mu \mathrm{m}$ dust fraction contains $1.84 \%$ which is $0.77 \mu \mathrm{g}$ of the complete PAH mass of $41.94 \mu \mathrm{g}$ adsorbed on $100 \mathrm{mg}$ total dust. The $\geqslant 24.95 \mu \mathrm{m}$ fraction contains $29.95 \%$ - that is, 12.56 $\mu \mathrm{g}$ PAH. The fine dust, which is $31.4 \%$ of the total dust, contains $49.9 \%$ of the total mass of PAH adsorbed.

Table 3 shows the concentrations of the particleadsorbed polycyclic aromatic hydrocarbons. These show that the fine dust contains almost $50 \%$ of the total PAH, both for the individual compounds and for the total mixture. The gas phase PAH concentrations are also listed. There were striking differences in some cases between the PAH concentrations in the

Table 1 Mean particle size $(\bar{x})$ of the seven fractions of the total dust and mean values of the percentage weight and standard deviation $(\bar{x} \pm s)$ of 13 separate determinations made at the site of an iron foundry where castings are shaken out from their moulds

\begin{tabular}{|c|c|c|c|c|c|c|c|}
\hline \multirow[b]{2}{*}{$\begin{array}{l}\text { Particle size } \\
(\mu \mathrm{m})\end{array}$} & \multicolumn{7}{|c|}{-Total dust: $9.58 \pm 4.72 \mathrm{mg} / \mathrm{m}^{3}$} \\
\hline & 0.36 & $0 \cdot 76$ & 1.57 & $3 \cdot 13$ & $6 \cdot 26$ & $12 \cdot 17$ & $\geqslant 24.95$ \\
\hline \multirow[t]{2}{*}{ Weight \% } & $1 \cdot 1 \pm 0.3$ & $2 \cdot 9 \pm 1 \cdot 1$ & $4.9 \pm 1.6$ & $8.7 \pm 1.5$ & $13 \cdot 8 \pm 2.4$ & $23 \cdot 8 \pm 1 \cdot 2$ & . $45.0 \pm 5.0$ \\
\hline & & -Fine & $t: 3.01 \pm 1.5$ & $/ \mathrm{m}^{3}$ & & & \\
\hline
\end{tabular}


Table 2 Polycyclic aromatic hydrocarbons (PAH) identified by glass capillary gas chromatography/mass spectrometry $(G C G C / M S)$ with classification of biological activity in subcutaneous and epicutaneous animal test systems. With the exception of benzo[a]pyrene no adequate data are available on their teratogenicity

\begin{tabular}{|c|c|c|c|}
\hline Compound & $\begin{array}{l}\text { Carcinogenicity } \\
\text { (Animal studies) }\end{array}$ & $\begin{array}{l}\text { Mutagenicity } \\
\text { (Ames test) }\end{array}$ & Reference \\
\hline $\begin{array}{l}\text { Phenanthrene } \\
\text { Anthracene } \\
\text { Fluoranthene } \\
\text { Pyrene } \\
\text { Benzo[a]fluorene } \\
\text { Benzo[b]fluorene } \\
\text { Benzo[b] naphtho[2,1-d]thiophene } \\
\text { Benzo[ghi]fluoranthene } \\
\text { Benz[a]anthracene } \\
\text { Chrysene/triphenylene } \\
\text { Benzo[b+j + k]fluoranthene } \\
\text { Benzo[e]pyrene } \\
\text { Benzo[a]pyrene } \\
\text { Perylene } \\
\text { Dibenz[a,j]anthracene } \\
\text { Indeno[1,2,3-cd]pyrene } \\
\text { Dibenz[a,h]anthracene } \\
\text { Benzo[ghi]perylene } \\
\text { Anthanthrene } \\
\text { Coronene }\end{array}$ & $\begin{array}{l}-; \mathrm{TI} \text { (very weakly) } \\
-; \mathrm{CC} \\
-; \mathrm{CC} \\
- \\
- \\
- \\
- \\
\pm /+; \mathrm{TI} \\
\pm /+; \mathrm{TI} \\
+/++/+++/ \text { TI } \\
-/+ \\
+++/++++/ ; \mathrm{TI} \\
- \\
++ \\
+/++; \mathrm{TI} \\
+++/++++/ ; \mathrm{TI} \\
-/+; \mathrm{CC} \\
\pm /++ \\
-/+; \mathrm{TI}\end{array}$ & $\begin{array}{l}- \\
+ \\
-1+ \\
- \\
+ \\
-1+ \\
+ \\
+ \\
++1+++ \\
+ \\
++++ \\
+ \\
++ \\
++1+++ \\
+ \\
+\end{array}$ & $\begin{array}{l}14,16,20 \\
13-16 \\
16,18,21 \\
13,16,19,21 \\
16,18 \\
16,18 \\
19,20 \\
16,18 \\
13,16,17,18 \\
13,14,16,20 \\
16,19-21 \\
16,19,20 \\
13,15-17,19 \\
13,14,18 \\
13,14,16,19,20 \\
13,16,17,19 \\
14,16,17,19 \\
13,14,17,20 \\
13,14,19 \\
13,16\end{array}$ \\
\hline
\end{tabular}

- No evidence for animal carcinogenicity/mutagenicity; \pm very weakly active; + weakly active; ++ moderately active; +++ very active; ++++ extremely active.

TI tumour initiator; $\mathrm{CC}$ cocarcinogenic with benzo[a]pyrene.

Biological activities published often differ and in some cases several reports are cited. ${ }^{13-21}$

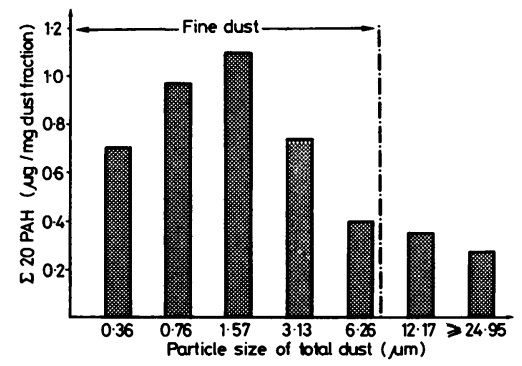

Fig 1 Total amount of 20 identified polycyclic aromatic hydrocarbons $(P A H)$ in $\mu \mathrm{g} / \mathrm{mg}$ total dust in seven particle size fractions.

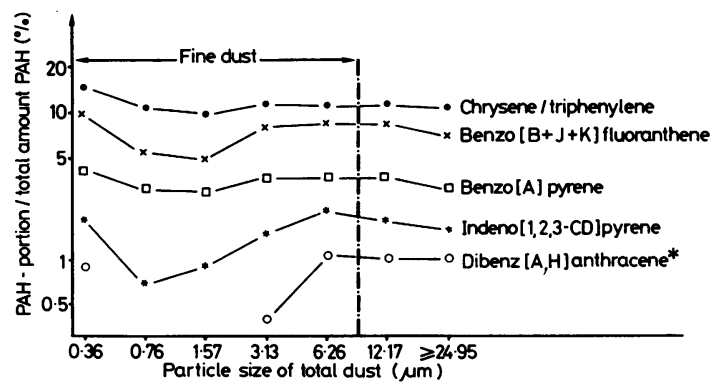

Fig 2 Amounts of five selected polycyclic aromatic hydrocarbons (PAH) as a percentage of total amount of 20 $P A H$ analysed in seven particle size fractions. These $P A H$ are included in German list of maximum concentrations at workplace. ${ }^{22} *$ Dibenz $[a, h]$ anthracene could not be found in the particle size fraction of 0.76 and $1.57 \mu \mathrm{m}$.

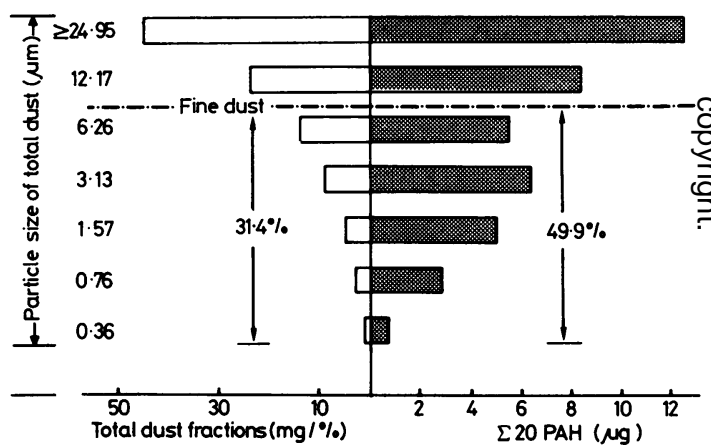

Fig 3 Mean values of weight percentage ( $m g-\%)$ of seven particle size fractions and adsorbed $\mathrm{PAH}(\mu \mathrm{g})$.

particulate and gas phases. For example, the concentration was about 100 times higher for anthanthrene in the gas phase than in the particle phase. Four of the five selected PAH $^{22}$ show similar trends, although they are less clear than in the case of anthanthrene. The PAH concentration is distributed about 3:1 in the gaseous and particle adsorbed phases.

\section{Discussion}

A complex mixture of PAH may be found at the site where the castings are shaken out of their moulds in an iron foundry; a total of 20 PAH were quantified. It was possible, in addition, to classify 13 more com- 
Table 3 Concentrations of 20 gaseous and dust adsorbed polycyclic aromatic hydrocarbons (PAH). Those calculated for the particle adsorbed PAH are based on the mean fine and total dust concentrations (table 1)

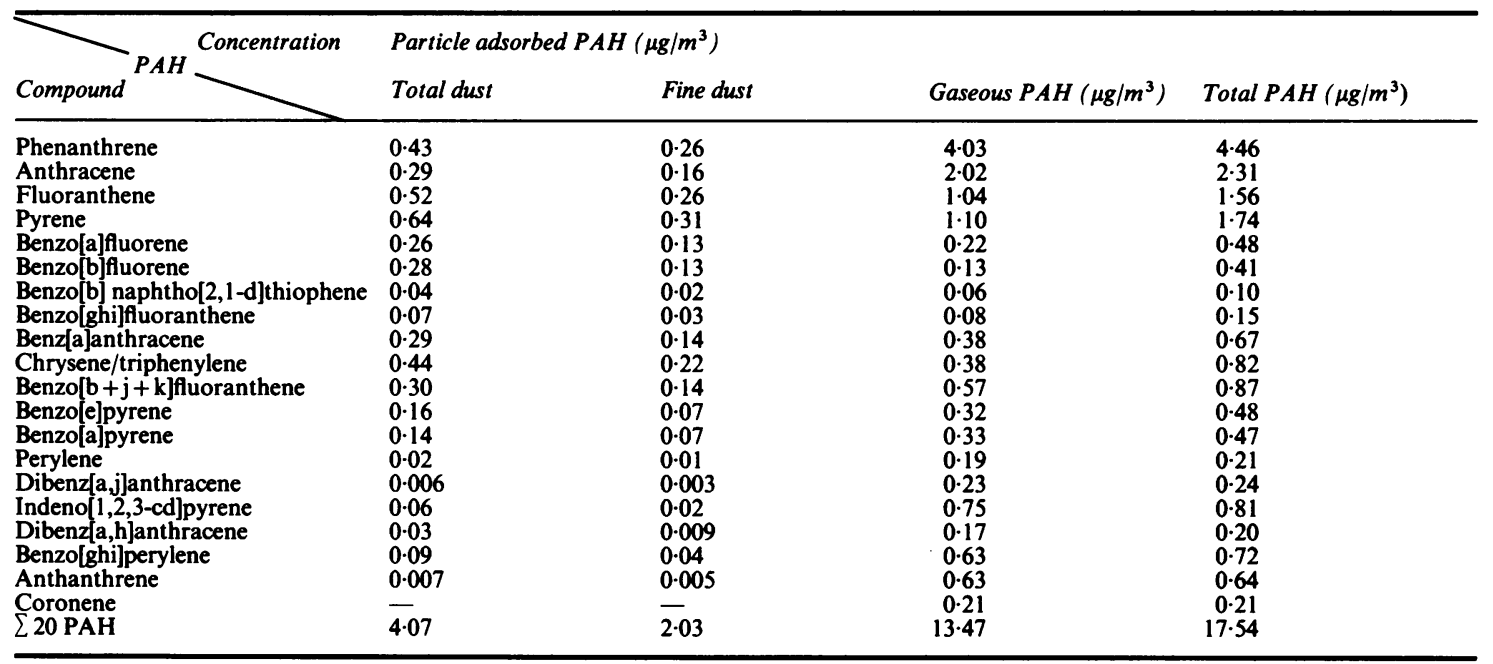

ponents of lower concentration by their molecular weight and to relate them to the PAH and to their methyl substituted derivatives.

It was not possible to confirm statements that these components usually appear in the atmosphere adsorbed on dust particles. ${ }^{23-25}$ As may be seen from table 3 , it was only in the case of benzo [a $+b]$ fluorene and chrysene/triphenylene that the concentrations were higher in the particulate matter than in the gas phase. The PAH with four and more rings, which are those of importance with respect to carcinogenicity, occur on average about $70 \%$ in the gas phase; $77 \%$ of the total PAH exposure at the workplace occur in the gas phase. At workplaces other than foundries these compounds could not be detected or were present only in insignificant concentrations in the gas phase as a result of low vapour pressure and because of a high degree of adsorption. ${ }^{26}$

An explanation for this fact may be found in the method used to shake out the castings. On site, the particles of sand still have a relatively high temperature of about $600-700^{\circ} \mathrm{C}$ thus inhibiting adsorption. It is here that the gaseous PAH predominate.

Particle size distribution is crucial for deposition in the various regions of the respiratory tract and only particles with an aerodynamic diameter of less than $7 \mu \mathrm{m}$ are deposited in the alveoli. Therefore the question of particle size distribution and the amount of adsorbed PAH is of interest for the assessment of medical risk. The size associated distribution of the total PAH mass must be evaluated critically, how- ever. As has been shown, a maximum PAH load occurs at $1.57 \mu \mathrm{m}$. On the other hand, the five selected PAH, some of which are distinctly carcinogenic, do not conform to this pattern. These, and some other homologous PAH for which a carcinogenic potential is suspected, appear in the individual particle size fractions of the total dust at similar concentrations.

The PAH with comparatively low molecular weight and high vapour pressure such as phenanthrene, anthracene, fluoranthene, or pyrene are largely engaged in forming the loading gradient. These compounds have the highest concentration in the gas as well as the particulate phase and amount to $57 \%$ of the total PAH concentration at this workplace. Their total, fine dust adsorbed and gaseous concentrations show similar percentage distributions. Comparable results have been reported at workplaces with comparable PAH formation and exposure. ${ }^{27}$

The question of possible localisation of cancer is of special importance. It is assumed that the fraction of dust deposited in the tracheobronchial tree is associated with lung cancer and that the dust fraction deposited in the nose, pharynx, and larynx is associated with laryngeal cancer. These dust fractions contain only about $15 \%$ of the total PAH mass.

There are no results indicating what amount of PAH is exhaled, metabolised, or absorbed unchanged in the upper, middle, or lower respiratory tract. On the other hand, there is sufficient evidence concerning the carcinogenicity of numerous PAH after local application, including that to the respiratory tract.

On the basis of our results, we recommend effective measures to control exposure to gas and dust in the 
areas of iron foundries where castings are shaken out of their moulds. The amounts of added carbon carriers and other admixtures liable to pyrolysis should be kept as low as is technically possible. This applies particularly to the recycling of moulding sands. Further technical investigation is required to determine to what extent substitutes and improvements of the technical procedure are possible.

Supported by the Bundesministerium für Forschung und Technologie of the Federal Republic of Germany, Project-No 01 VD 093.

\section{References}

1 Gwin C, Scott W, James R. A preliminary investigation of the organic chemical emission from green sand pyrolysis. Am Ind Hyg Assoc J 1976;37:685-9.

2 Elliehausen HJ, Knecht U, Maaß-Rühl B. Schadstoffbelastung durch Formsande einer Eisengießerei. Stuttgart: Gentner Verlag, 1984:283-8.

3 Goldsmith FD, Guidotti TL, Johnston DR. Does occupational exposure to silica cause lung cancer? Am J Ind Med 1982; 3:423-40.

4 Fletcher AC, Ades A. Lung cancer mortality in a cohort of English foundry workers. Scand J Work Environ Health 1984; 10:7-16.

5 Palmer WG, Scott WD. Lung cancer in ferrous workers: a review. Am Ind Hyg Assoc J 1981;42:329-40.

6 Tola S, Koskela RS, Hernberg S, Järvinen E. Lung cancer mortality among iron foundry workers. J Occup Med 1979;21:753-60.

7 Deutsche Forschungsgemeinschaft. Arbeitsgruppe Festlegung von Grenzwerten für Stäube. Gesundheitsgefährliche Arbeitsstoffe. Toxikologisch-arbeitsmedizinische Begründung von MAK-Werten. Weinheim: Verlag Chemie, Band IV; 1984.

8 Lemen RA, Dunnom DD, Wagner WD. Standards for quartz dust exposure - a NIOSH view. In: Goldsmith DF, ed. Silica, silicosis and cancer: controversy in occupational medicine. New York, London: Praeger, 1985:142-9. (Cancer research monographs: vol 2.)

9 Simonato L, Sarraci R. Epidemiological research and silica dust exposure: The role of the IARC. In: Goldsmith DF, ed. Silica, silicosis and cancer: controversy in occupational medicine. New York, London: Praeger, 1985:286-93. (Cancer research monographs: vol 2.)

10 VDI 2265. Feststellung der Staubsituation am Arbeitsplatz zur gewerbehygienischen Beurteilung. VDI-Handbuch Reinhaltung d. Luft; Bd. 4, Beuth Verlag, Berlin, Köln 1980, 2-15.

11 Grimmer G, Böhnke H. Gas chromatographic profile analysis of polycyclic aromatic hydrocarbons in lubricating oil, cutting oil and fuel. Lyon: International Agency for Research on Cancer, 1979:155-73. (IARC publications, No 29.)

12 Griest WH, Caton JE. Extraction of polycyclic aromatic hydrocarbons for quantitative analysis. In: Bjorseth A, ed. Handbook of polycyclic aromatic hydrocarbons. New York, Basel: Marcel Dekker, Inc, 1983:94-148.

13 Dipple A. Polynuclear aromatic hydrocarbons. In: Searle CHE, ed. Chemical carcinogens. Washington: Library of Congress Data, 1978:245-314. (American Chemical Society Monograph 173.)

14 Cavalieri E, Rogan E, Roth R. Multiple mechanisms of activation in aromatic hydrocarbon carcinogenesis. In: Floyd RA, ed. Free radicals and cancer. New York, Basel. Marcel Dekker Inc, 1982:117-58.

15 Sandmeyer EE. Aromatic hydrocarbons. In: Clayton GD, Clayton FE, eds. Patty's industrial hygiene and toxicology. Vol 2B. New York: John Wiley and Sons, 1981:3253-431.

16 International Agency for Research on Cancer. IARC monographs on the evaluation of the carcinogenic risk of chemicals to humans. Polynuclear aromatic compounds. Part 1. Chemical, environmental and experimental data. Lyon: IARC, 1983.

17 Pott F, Werner W. Analytik und Bewertung kanzerogener polyzyklischer aromatischer Kohlenwasserstoffe aus lufthygienisch-toxikologischer Sicht. Z Gesamte Hyg 1983; 29:505-7.

18 Schmähl D, Deutsch-Wenzel P, Brune H, et al. Biological activity. In: Grimmer G, ed. Environmental carcinogens: polycyclic aromatic hydrocarbons. Boca Raton, Florida: CRC Press, Inc, 1983:157-219.

19 Jakob J, Karcher W, Wagstaffe PJ. Polycyclic aromatic compounds of environmental and occupational importance - their occurrence, toxicity and development of high purity certified reference materials. Part I. Fresenius Zeitschrift für Analytische Chemie 1984;317:101-4.

20 Lee ML, Novotny MV, Bartle KD. Analytical chemistry of polycyclic aromatic compounds. New York: Academic Press Inc, 1981:441-9.

21 Van Duuren BL, Goldschmidt BM. Carcinogenic and tumorpromoting agents in tobacco carcinogenesis. $J$ Natl Cancer Inst 1976;56:1237-42.

22 Commission for the investigation of health hazards of chemicar compounds in the work area. DFG German Science Foundation. Maximum concentrations at the workplace and biologicaf tolerance values for working materials. Weinheim: Verlag Chemie, 1985. Report No XXI.

23 Pierce RC, Katz M. Dependency of polynuclear aromatic hydrocarbon content on size distribution of atmospheric aerosols. Environ Sci Technol 1975;9:347-53.

24 Bjorseth A, Bjorseth O, Fjeldstad PE. Polycyclic aromatic hydrocarbons in working atmospheres. Part II: determination of the PAH-content in a coke plant. Scand J Work Environ Health 1978;4:224-36.

25 Pott F, Oberdörster B, Jacob J, Grimmer G. Behavior of PAH in the organism. In: Grimmer G, ed. Environmental carcinogens: polycyclic aromatic hydrocarbons. Boca Raton, Florida: CRC Press, Inc, 1983:129-56.

26 Bjorseth A. Polycyclic aromatic hydrocarbons in the work atmosphere. Scand J Work Environ Health 1981;7:223-32.

27 Schimberg WR. Industrial hygienic measurements of polycyclic aromatic hydrocarbons in foundries. In: Cook M, Dennis AJ, eds. Chemical analysis and biological fate. Polynuclear aromatic hydrocarbons. Fifth International Symposium. Columbus, Ohio: Battelle Press, 1981:755-62. 